\title{
Overview Regarding the Bioactivity of Agastache foeniculum and Nepeta cataria Species
}

\author{
Simona DUDA, Liviu Al. MĂRGHITAŞ, Dan DEZMIREAN, Otilia BOBIŞ \\ Department of Technological Sciences, Faculty of Animal Science and Biotechnologies, \\ University of Agricultural Sciences and Veterinary Medicine Cluj-Napoca, Romania \\ *Corresponding author, email: obobis@usamvcluj.ro
}

Bulletin UASVM Animal Science and Biotechnologies 72(1) / 2015

Print ISSN 1843-5262; Electronic ISSN 1843-536X

DOI:10.15835/buasvmcn-asb:10591

\begin{abstract}
In this study, we summarize the recent advances on chemical composition and bioactivity of giant hyssop (Agastache foeniculum (Pursh) Kuntze) and catnip (Nepeta cataria L.). Extracts from giant hyssop and catnip have a significant bioactivity, antibacterial and antioxidant activity (Suschke et al., 2007; Zielińska and Matkowski, 2014; Mihaylova et al., 2013). This literature review wants to emphasize the value of these two plants and the opportunity of using them to obtain bioactive extracts with applicability in beekeeping for different pest control. Different parts of the mentioned plants were used for the determination of active principles from macerates and essential oils. Spectrophotometric methods as well as high performance liquid chromatography and gas chromatography are generally used for determination of bioactive principles from the classes of polyphenols, flavonoids, carotenoids and aromatic acids. Remarkable results have been obtained using the essential oil from Agastache foeniculum as an insecticide for the control of pests like the Red flour beetle (Tribolium castaneum Herbst), Lesser grain borer (Rhyzopertha dominica F), Mediterranean flour moth (Ephestia kuehniella) and the Indian meal moth (Plodia interpunctella) from the grain and food warehouses (Ebadollahi, 2011). The anti-microbial activity of catnip (Nepeta cataria) was proven in over five bacterial strains: Staphylococcus aureus, Klebsiella pneumoniae, Pseudomonas aeruginosa, Escherichia coli and Bacillus subtillis (Bandh et al., 2011).

Considering the results obtained and reported in the literature on the control of various pests and diseases, we consider appropriate to extend the research in the field of beekeeping as well, for a natural treatment of different bacterial diseases and pests.
\end{abstract}

Keywords: Agastache foeniculum, Nepeta cataria, anti-microbial, bio-insecticides

\section{INTRODUCTION}

In this study, we summarize the recent advances on chemical composition and bioactivity of aerial parts (leaves, stems and inflorescences) of giant hyssop (or blue giant hyssop, licorice mint) (Agastache foeniculum (Pursh) Kuntze) and catnip (Nepeta cataria L.). The genus Agastache includes 22 species of perennial aromatic medicinal herbs (Vogelmann, 1983). Although the study of the two species ( $A$. foeniculum and $N$. cataria) has been carried out since 1945, for Agastache (Lint and Epling, 1945), and since 1941 for Nepeta (McElvain et al., 1941; Walker cited by Woods and DuBuy, 1951), there is still much to be elucidated in the chemical composition of plants and their effects. Giant hyssop has been commercially cultivated as a source of nectar for honeybees (Apis mellifera L.) in Washington (Mayer et al., 1982, cited by Widrlechner, 1992; Senechal, 1990; Ayers and Widrlechner, 1994; Fuentes-Granados et al., 1998), because it excels at nectar production (Wilson et al., 1992). Extracts from giant hyssop and catnip have a significant bioactivity, antibacterial and antioxidant activity (Mihaylova et al., 2013; Zielińska and Matkowski, 2014). 
This review covers the literature to summarize the main constituents from both aromatic and medicinal plants. $N$. cataria (Catnip) is the most famous Nepeta species, which has a long history of use as tea in Europe before real tea was imported from the orient (Herron, 2003). The flowering tips of the plant have also being used as a sedative drug (Newall et al., 1996; Baser et al., 2000). Some of the Nepeta species are used by bees as a source of pollen and nectar (Sammataro and Avitabile 1998, cited by Celenk et al., 2008).

Catnip is a perennial herb with a considerable folkloric reputation (Marchei et al., 2010). A diethyl ether extract of this plant has been shown to have antimicrobial activity against fungi and Gram-positive bacteria, have bacteriostatic and fungistatic properties (Bourrel et al., 1993; Nostro et al., 2001), and also with traditional uses that relate to the treatment of inflammation (Prescott et al., 2011). Catnip produces predominantly nepetalactone, which is also known to comprise aphid sex pheromones and aphid parasitoid attractants. The availability of aphid sex pheromone components is now facilitating the development of new aphid pest control strategies, incorporating the use of other semiochemicals, particularly in the manipulation of populations of aphid parasitoids and aphid predators (Birkett and Pickett, 2003; Birkett et al., 2010). Ameixa and Kindlmann (2012) have found a positive response regarding the aphid parasitoid Aphidius colemani, conducting research with a mixture of odors of synthetic and plant-extracted nepetalactone (a component of aphid sex pheromone) and (E)- $\beta$ farnesene (aphid alarm pheromone).

This literature review wants to emphasize the value of these two plants and the opportunity of using them to obtain bioactive extracts with applicability in beekeeping, for different pest control.

\section{MATERIALS AND METHODS}

Different parts of the mentioned plants were used for the determination of active principles from macerates and essential oils (Nykänen et al., 1989). Spectrophotometric methods as well as high performance liquid chromatography and gas chromatography is generally used for the determination of bioactive principles from the classes of polyphenols, flavonoids, carotenoids and aromatic acids (Vogelmann, 1984; Tisserand and Young, 2014).

Essential oil from aerial parts of giant hyssop was isolated by the hydrodistillation with Clevenger apparatus, and its chemical composition was studied by gas chromatography mass spectrometry (Shakhnoza and Glushenkova, 2012; Srifi et al., 2012; Zielińska and Matkowski, 2014). The chemical composition of catnip essential oils can be determined by GC-MS on an apolar stationary phase by comparison of the characteristic fragmentation patterns with those of the Wiley 275L database. Essential oils were then fractionated by column chromatography packed with silica gel (Heuskin et al., 2009; Ganzera et al., 2001).

To determine the potential crop protection value of Nepeta cataria essential oils, the repellent activity of the oils was assessed using a four-way olfactometer assay, with both oils showing strong repellent effects (Peterson and Coats, 2001; Schultz et al., 2004; Webb and Russell, 2007; Birkett et al., 2010). Nepetalactones were analyzed by reversedphase HPLC coupled with UV and MS detection. The linearity range for $Z, E$-nepetalactone was determined as $0.00655-0.655 \mathrm{mg} / \mathrm{mL}$ with a correlation coefficient of 0.9999 , and the linearity range of $E, Z$-nepetalactone was found to be $0.00228-0.456 \mathrm{mg} / \mathrm{mL}$ with a correlation coefficient of 0.9999 , under UV detection at $228 \mathrm{~nm}$. The linearity ranges were from 0.00164 to 0.0328 $\mathrm{mg} / \mathrm{mL}$, with a correlation coefficient of 0.9999 , for $Z, E$-nepetalactone and $0.00114-0.0228 \mathrm{mg} /$ $\mathrm{mL}$, with a correlation coefficient of 0.9999 , for $E$, $Z$-nepetalactone by MS detection with selected ion monitoring of ion peak $m / z 167$. The MS detection was found to be more sensitive than UV detection and this method was validated as simple, reliable and sensitive for catnip nepetalactone analysis (Wang et al., 2007).

Nostro et al. (2000) used two methods of extraction from $N$. cataria. In method A, a known amount of $50 \mathrm{~g}$ powdered drug (which was sequentially extracted at room temperature with petroleum ether $\left(30^{\circ} \mathrm{C}, 50^{\circ} \mathrm{C}\right)$, dichloromethane, dichloromethane: methanol (9:1) and methanol (Arebalo and Mitchell, 1984; Chalchat and Lamy, 1997). The four extracts were concentrated to dryness using a rotary evaporator at $40^{\circ} \mathrm{C}$. In method B, a known amount of 50 g powdered drug was extracted as reported by Al-Sarraj et 
al. (1985), cited by Nostro et al., 2000. The drug was suspended in enough distilled water to form a homogeneous suspension. The mixture was adjusted to $\mathrm{pH} 2.0$ with $\mathrm{HCl}\left(1_{N}\right)$ and then incubated at $37^{\circ} \mathrm{C}$ for $30 \mathrm{~min}$ in a shaking waterbath. The mixture was then neutralized with $\mathrm{NaOH}$ $\left(1_{N}\right)$ to $\mathrm{pH} 7.0$, filtered, extracted with diethyl ether and concentrated to dryness. The remaining aqueous extract was lyophilized. All solvents were purchased from Merck (Milan, Italy). The method $B$ proved to be more efficient in extracting the active compounds and this could be ascribed to the acidified aqueous environment, which promotes an easy extraction.

\section{RESULTS AND DISSCUSION}

To Agastache, in addition to the main components (phenylpropanoids, terpenoids and essential oils) there are many other such biocompounds: phenolic compounds (non-volatile metabolites), such as caffeic acid derivatives (especially rosmarinic acid) flavones and flavone glycosides (like acacetin, tilianin, agastachoside, and a rare dimeric malonyl flavone -agastachin) (Zielińska and Matkowski, 2014). Well, from aerial parts of agastache two unique lignans -agastenol and agastinol were isolated. Among terpenoids is noted: triterpenoids of oleananetype -maslinic acid, oleanolic acid and $\beta$-amyrin-, ursane-type - ursolic acid, corosolic acid and $\alpha$-amyrin-, and typical plant sterols (abietane-type oxidized diterpenes - e.g., agastaquinone, agastol, and others (Zielińska and Matkowski, 2014).

In the essential oil from Agastache foeniculum were identified over 50 compounds, which were isolated. Only ten constituents, however, accounted for more than $0.1 \%$. In this essential oil prevailing, were the methyl chavicol (87.5\%)(Omidbaigi and Sefidkon, 2003) to (91-95\%) (Mazza and Kiehn, 1992) and limonene (2.4\%) (Omidbaigi and Sefidkon, 2003) to (3.6-3.9\%) (Mallavarapu et al., 2004), 1,8-cineole (2.0\%) and globulol (1.4\%) (Omidbaigi and Sefidkon, 2003) as the major constituents. Other components of the essential oil are: monoterpenes, sesquiterpenes, oxygenated monoterpenes, oxygenated sesquiterpenes, camphene, myrcene and phenolics among others (Wilson et al., 1992; Yashika et al., 2013).

Remarkable results have been obtained in use of the essential oil from Agastache foeniculum as an insecticide for the control of pests like the Red flour beetle (Tribolium castaneum Herbst), Lesser grain borer (Rhyzopertha dominica F), Mediterranean flour moth (Ephestia kuehniella) and the Indian meal moth (Plodia interpunctella) from the grain and food warehouses (Ebadollahi, 2011). A. foeniculum oil revealed a strong toxicity (strong larvicidal potential) against the $T$. castaneum larvae, but also decreased the activity of esterase and GST besides reducing total carbohydrate, lipid and protein contents. Results showed that the mortality of larvae was dose-dependent and increasing concentrations of the essential oil exacerbate mortality. Probit analysis showed that $\mathrm{LC}_{50}$ and $\mathrm{LC} 90$ values were calculated as $8.022 \%$ and $80.152 \%$, respectively (Ebadollahi et al., 2013). Lopez et al. (cited by Ebadollahi et al., 2013) reported estragole as an example of toxic compounds that are active against insect pests. The toxicity of $A$. foeniculum essential oil against red flour beetle, Tribolium castaneum (Herbst) and lesser grain borer Rhyzopertha dominica (F) was evaluated by fumigation (Ebadollahi, 2011; Zielińska and Matkowski, 2014).

In astudy by NafzigerandFadamiro (2011) with giant hyssop as nectar sources for the parasitoid wasp, Microplitis croceipes (Hymenoptera: Braconidae), found significantly increased female longevity and numerically increased male longevity with honey from this plant. However, giant hyssops are not good nectar sources for the wasp (Nafziger and Fadamiro, 2011).

Some of the effects of induced plant protection Herba Agastache and inflorescences are: antimicrobial, antiviral, antimutagenic, antiproliferative, antiatherogenic, cytotoxic to cancer cell, anti-nociceptive, anti-inflammatory, antioxidant, relaxant activity on the contractions and others (Yashika et al., 2012; Zielińska and Matkowski, 2014; Sánchez-Recillas et al., 2014).

The presence of Nasonov pheromone components in the floral aroma of particular populations of Agastache could bias bee preference and might be useful as a tool for researchers to select attractive types (Wilson et al., 1992). One component of the headspace of $A$. foeniculum, bornyl acetate, has being hown to stimulate the antennae of honeybees (Thiery et al., 1990, cited by Wilson, 1992), but this olfactory stimulation has not been correlated with attractiveness. Among the 27 compounds identified of Nepeta cataria essential oil, four major components 
were noted: 1,8-cineole (21.00\%), $\alpha$-humulene (14.44\%), $\alpha$-pinene $(10.43 \%)$ and geranyl acetate (8.21\%)(Peterson et al., 2002; Morteza-Semnani and Saeedi, 2004; Gilani et al., 2009; Javidnia et al., 2002).

The antimicrobial activity of aerial parts of Nepeta cataria was assayed against five bacterial strains Staphylococcus aureus, Klebsiella pneumoniae, Pseudomonas aeruginosa, Escherichia coli and Bacillus subtilis. Two fungal strains, Aspergillus flavus and Candida albicans were also used to evaluate anti-fungal activity (Adiguzel et al., 2009; Bandh et al., 2011). Also, Nestorović et al. (2010) observed and evaluated the antimicrobial activity of methanol extracts from Nepeta, assayed against eight bacterial and eight fungal species. All the tested extracts showed significant antibacterial and strong antifungal activity.

The research done by Zenasni et al. (2008) shows that Escherichia coli and Staphylococcus aureus are more sensitive than Pseudomonas aeruginosa to essential oil from the Nepeta genus $(\mathrm{p}<0.001)$. The research made by Zhu et al. (2014), found more than $98 \%$ inhibition of stable fly larval Stomoxys calcitrans (Diptera: Muscidae) growth and female oviposition was observed in larval and oviposition media treated with encapsulated catnip oil $(0.5 \mu \mathrm{g})$. Further, dose-response tests showed that as little as $0.1 \mu \mathrm{g}$ of encapsulated catnip oil provided more than $85 \%$ oviposition deterrence. Encapsulated catnip oil also exhibited antibacterial activity, supporting the hypothesis that its inhibition of larval growth may be based on its killing of the bacteria on which larvae feed. The use of encapsulated catnip oil can provide an alternative control strategy for stable fly management (Zenasni et al., 2008; Bandh et al., 2011; Zhu et al., 2014).

Pavela (2005) tested Nepeta cataria essential oils for insecticidal activity against larvae Spodoptera littoralis, which were highly toxic, with $\mathrm{LC}_{50} \leq 10.0 \mathrm{ml} / \mathrm{m}^{3}$.

By commercial cultivation of the catmint Nepeta cataria (Lamiaceae), the lactone (II) can be isolated by industrial scale steam distillation and converted to the lactol (I) by inexpensive chemical means (Birkett \& Pickett, 2003). Birkett et al. (2011) obtained results which suggest that although the nepetalactone isomers have the potential to be used in human and livestock protection against major pathogen vectors, intact, i.e. un-fractionated, Nepeta sp. oils offer potentially greater protection, due to the presence of both nepetalactone isomers and other components such as $(E)-(1 R, 9 S)$-caryophyllene.

Extracts of catnip were found to inhibit calcineurin; an important regulator of T-cell mediated inflammation that has received little attention in ethnopharmacological research. Calcineurin inhibition should be considered as a potential mode of action when investigating the immunomodulatory activity of caffeoyl phenylethanoid glycoside contained in catnip (Prescott et al., 2011). It has also been found that iridodial is a key intermediate in the biosynthesis of nepetalactone (Bellesia et al., 1984). Nepeta cataria, is also known to repel other ectoparasites affecting human and animal health (Kim et al., 2003; Khan et al., 2012). Zhu et al. (2009) successfully conducted catnip repellency tests on two fly species (stable flies and houseflies), including toxicity studies in humans to $N$. cataria products applied by oral, dermal and inhalation tests evaluating the eye and skin sensitivity. Bernardi et al. (2011) found through his research with catnip in rats improved male rat sexual
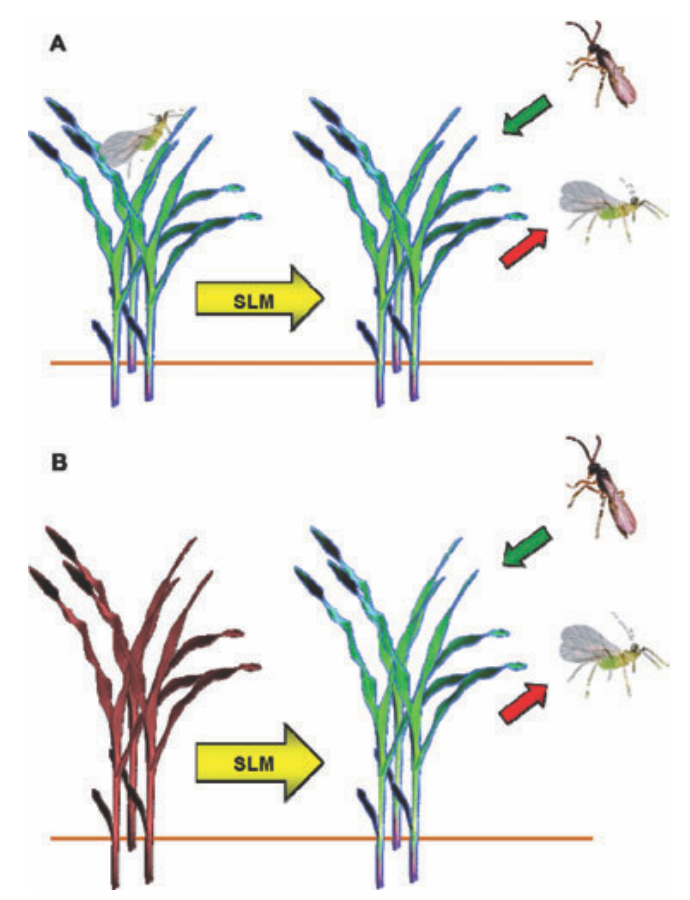

Fig. 1. Plant-defence compounds 'attracting' parasitoids and 'repelling' aphids could be activated by naturally occurring small lipophilic molecules (SLM) identified from (A) pest-damaged or (B) nonhost plants (Pickett et al., 2012). 
activity. The repellent mechanism could be activated by naturally occurring small lipophilic molecules (SLMs) identified from pest-damaged or non-host plants, as shown in Figure 1 (A and B, respectively) (Pickett et al., 2012).

Birkett et al. (2010)'s findings illustrate that Nepeta cataria possess a diverse range of high value secondary metabolites, and also highlight their potential to be developed as renewable feed stocks for the production of repellents for the use of economically important crop pests, as well as for the production of sex pheromones and natural enemy attractants. Further studies are underway to investigate their potential for use as part of a novel strategy for dust mite control, based on deployment of repellent and attractant semiochemicals in a push-pull strategy (Cook et al., 2007, cited by Khan et al., 2012), which could incorporate attractive pull components such as the recently identified aggregation pheromone (Skelton et al., 2010, cited by Khan et al., 2012).

Polsomboon et al. (2008) made experiments, which showed that catnip oil has strong irritant and repellent actions on mosquito test populations as indicated by the comparatively low escape time. Catnip oil and its major constituent compounds, nepetalactone, act not only as effective feeding and oviposition repellents, but also have a strong spatial repellency. The in vitro blood-feeding assay has proven to be a useful screening tool for discovering novel repellents for stable flies. Field trials conducted on cattle of two catnip oil formulations found these gave 5-6 h of protection against stable flies. Formulating catnip oil to meet USDA organic standards may also have promise as a method for stable fly control in organic dairy farms (Bissinger et al., 2010; Zhu et al., 2012).

\section{CONCLUSION}

Biotechnological and molecular studies have focused on in vitro propagation and enhancing the biosynthesis of bioactive metabolites in cell or organ cultures, as well as on the expression of genes involved in phenolic biosynthesis (Zielińska and Matkowski, 2014).

Nepeta cataria possesses spasmolytic and myorelaxant activities mediated possibly through dual inhibition of calcium channels and PDE, which may explain its traditional use in colic, diarrhea, cough and asthma (Gilani et al., 2009).
The use of essential oils in the control of veterinary ectoparasites is an exciting area, which holds huge potential for the future. However, extensive field trials, standardization of components, standardization of extraction techniques, standardization of experimental design, mammalian toxicology profiling and excipient development, as well as further investigation into the residual activities and length of shelf life of these oils are all required before their potential can be fully explored (Ellse and Wall, 2014).

The results regarding the identified and isolated active principles from catnip and their antimicrobial effects encourage further research for their usage in the cosmetic and food industry, as viable and safe alternatives to synthetic antimicrobial products. Considering the results obtained and reported in the literature in the control of various pests and diseases, we consider appropriate to extend the research also in the field of beekeeping, for natural treatment of different bacterial diseases and pests. We consider appropriate, to extend further the research on the utility of the two plants on the health of bees and their honey production.

Acknowledgements. This paper was published under the frame of European Social Fund, Human Resources Development Operational Programme 2007-2013, project no. POSDRU/159/ 1.5/S/132765.

\section{REFERENCES}

1. Adiguzel A, H Ozer, M Sokmen, M Gulluce, A Sokmen, H Kilic, F Sahin, O Baris (2009). Antimicrobial and antioxidant activity of the essential oil and methanol extract of Nepeta cataria. Polish Journal of Microbiology, Vol. 58, Issue 1, 6976.

2. Ameixa OMCC and P Kindlmann (2012). Effect of synthetic and plant-extracted aphid pheromones on the behaviour of Aphidius colemani. J Applied Entomology, 136(4): 292301.

3. Arebalo RE, ED Mitchell Jr (1984). Cellular distribution of 3-hydroxy-3-methylglutaryl coenzyme a reductase and mevalonate kinase in leaves of Nepeta cataria. Phytochemistry, Vol. 23, Issue 1, 13-18.

4. Ayers GS, and MP Widrlechner (1994). The genus Agastache as bee forage: a historical perspective. American Bee Journal (USA), Vol. 134, Issue 5.

5. Bandh SA, AN Kamili, BA Ganai, BA Lone \& S Saleem (2011). Evaluation of antimicrobial activity of aqueous extracts of Nepeta cataria. J Pharm Res, 4(9), 3141-3142. 
6. Baser KHC, N Kirimer, M Kurkcuoglu, B Demirci (2000). Essential Oils of Nepeta Species Growing in Turkey. Chemistry of Natural Compounds. Vol. 36, Issue 4, 356359.

7. Bellesia F, R Grandi, UM Pagnoni, A Pinetti, R Trave (1984). Biosynthesis of nepetalactone in Nepeta cataria. Phytochemistry, Vol. 23, Issue 1, 83-87.

8. Bernardi Maria Martha, Thiago Berti Kirsten, João Henrique Ghilardi Lago, Tatiana Marisis Giovani, Cristina de Oliveira Massoco (2011). Nepeta cataria var. citriodora (Becker) increases penile erection in rats. Journal of Ethnopharmacology, Vol. 137, Issue 3, 1318-1322.

9. Birkett MA, JA Pickett (2003). Aphid sex pheromones: from discovery to commercial production. Phytochemistry, Vol. 62, Issue 5, 651-656.

10. Birkett MA, TJA Bruce, JA Pickett (2010). Repellent activity of Nepeta grandiflora and Nepeta clarkei (Lamiaceae) against the cereal aphid, Sitobion avenae (Homoptera: Aphididae). Phytochemistry Letters, Volume 3, Issue 3, 139-142.

11. Birkett MA, A Hassanali, S Hoglund, J Pettersson, JA Pickett (2011). Repellent activity of catmint, Nepeta cataria, and iridoid nepetalactone isomers against Afrotropical mosquitoes, ixodid ticks and red poultry mites. Phytochemistry, Vol. 72, 109-114.

12. Bissinger Brooke W and RM Roe (2010). Tick repellents: past, present, and future. Pesticide biochemistry and physiology, Vol. 96, Issue 2, 63-79.

13. Bourrel C, F Perineau, G Michel \& JM Bessiere (1993). Catnip (Nepeta cataria L.) essential oil: analysis of chemical constituents, bacteriostatic and fungistatic properties. Journal of Essential Oil Research, Vol. 5, Issue 2, 159-167.

14. Chalchat Jean-Claude and Jacques Lamy (1997). Chemical composition of the essential oil isolated from wild catnip Nepeta cataria L. cv. citriodora from the Drôme region of France. Journal of Essential Oil Research, Vol. 9, Issue 5, 527-532.

15. Celenk Sevcan, Tuncay Dirmenci, Hulusi Malyer (2008). A palynological study of the genus Nepeta L. (Lamiaceae). Plant Systematics and Evolution, Vol. 276, Issue 1-2, 105123.

16. Ebadollahi A, M Safaralizadeh, A Pourmirza, S Gheibi (2010). Toxicity of Essential Oil of Agastache foeniculum (Pursh) Kuntze to Oryzaephilus surinamensis L. and Lasioderma serricorne F. Journal of Plant Protection Research, Vol. 50, Issue 2, 215-219.

17. Ebadollahi Asgar (2011). Chemical constituents and toxicity of Agastache foeniculum (Pursh) Kuntze essential oil against two stored-product insect pests. Chilean J Agricultural Res, 71:2, 212-217.

18. Ebadollahi A, Khosravi R, Jalali-Sendi J, Honarmand $P$ \& Moayed-Amini R (2013). Toxicity and physiological effects of essential oil from Agastache foeniculum (Pursh) Kuntze against Tribolium castaneum Herbst (Coleoptera: Tenebrionidae) larvae. Ann Review \& Res in Biology, 3: 649-658.
19. Ellse L and R Wall (2014). The use of essential oils in veterinary ectoparasite control: a review. Medical and Veterinary Entomology, Vol. 28, Issue 3, 233-243.

20. Fuentes-Granados RG and MP Widrlechner (1995). Diversity Among and Within Populations of Agastache foeniculum. Proceedings of the $14^{\text {th }}$ North American Prairie Conference. Kansas State University, Manhattan, Kansas, Ed. D. Hartnett, 1-8.

21. Fuentes-Granados RG, MP Widrlechner and LA Wilson (1998). An overview of Agastache research. Journal of Herbs, Spices \& Medicinal Plants, Vol. 6, Issue, 69-97.

22. Ganzera M, S Crockett, MR Tellez \& IA Khan (2001). Determination of nepetalactone in Nepeta cataria by reversed phase high performance liquid chromatography. Die Pharmazie, 56(11), 896.

23. Gilani Anwar H, Abdul J Shah, Amina Zubair, Sana Khalid, Jawad Kiani, Amir Ahmed, Munawwer Rasheed, Viqar U Ahmad (2009). Chemical composition and mechanisms underlying the spasmolytic and bronchodilatory properties of the essential oil of Nepeta cataria L. Journal of Ethnopharmacology, Vol. 121, Issue 3, 405-411.

24. Herron Scott (2003). Catnip, Nepeta cataria, a morphological comparison of mutant and wild type specimens to gain an ethnobotanical perspective. Economic Botany, 57(1): 135-142.

25. Heuskin Stéphanie, Bruno Godin, Pascal Leroy, Quentin Capella, Jean-Paul Wathelet, François Verheggen, Eric Haubruge, Georges Lognay (2009). Fast gas chromatography characterisation of purified semiochemicals from essential oils of Matricaria chamomilla L. (Asteraceae) and Nepeta cataria L. (Lamiaceae). J. Chromatography A, Vol. 1216, Is 14, 27682775.

26. Javidnia K, R Miri, F Safavi, A Azarpira and A Shafiee (2002). Composition of the essential oil of Nepeta persica Boiss from Iran. Flavour and Fragrance J., Vol. 17, Issue 1, 20-22.

27. Khan MA, I.Jones, E Loza-Reyes, MM Cameron (2012). Interference in foraging behaviour of European and American house dust mites Dermatophagoides pteronyssinus and Dermatophagoides farinae (Acari: Pyroglyphidae) by catmint, Nepeta cataria (Lamiaceae). Experimental and Applied Acarology, Vol. 57, Issue 1, 6574.

28. Kim Soon-Il, Chan Park, Myung-Hee Ohh, Hyung-Chan Cho, Young-Joon Ahn (2003). Contact and fumigant activities of aromatic plant extracts and essential oils against Lasioderma serricorne (Coleoptera: Anobiidae). J. of Stored Products Research, Vol. 39, Issue 1, 2003, 11-19.

29. Lint Harold and Carl Epling (1945). A revision of Agastache. American Midland Naturalist, Vol. 33, No. 1, 207-230.

30. Mallavarapu GR, RN Kulkarni, K, Baskaran and S Ramesh (2004). The essential oil composition of anise hyssop grown in India. Flavour and Fragrance J., Vol. 19, Issue 4, 351-353.

31. Marchei P, S Diverio, N Falocci, J Fatjó, JL Ruiz-de-laTorre, X Manteca (2010). The effect of Nepeta cataria on 
kittens' behavior. Journal of Veterinary Behavior: Clinical Applications and Research, Vol. 5, Issue 1, 50-51.

32. Massoco CO, MR Silva, SL Gorniak, MS Spinosa \& MM Bernardi (1995). Behavioral effects of acute and longterm administration of catnip (Nepeta cataria) in mice. Veterinary and human toxicology, Vol. 37, Issue 6, 530-533.

33. Mazza G, FA Kiehn (1992). Essential oil of Agastache foeniculum, a potential source of methyl chavicol. Journal of Essential Oil Research, Vol. 4, Issue 3, 295-299.

34. McElvain $M$ Samuel, Robert $\mathrm{D}$ Bright and Paul $\mathrm{R}$ Johnson (1941). The constituents of the volatile oil of catnip. I. Nepetalic acid, nepetalactone and related compounds. Journal of the American Chemical Society 63.6 (1941): 1558-1563.

35. Mihaylova D, L Georgieva and A Pavlov (2013). In vitro antioxidant activity and phenolic composition of Nepeta cataria L. extracts. Int. J.Agric.Sci.Technol, Vol. 1, Issue 4, 74-79.

36. Morteza-Semnani Katayoun and Madjid Saeedi (2004). Essential oils composition of Nepeta cataria L. and Nepeta crassifolia Boiss. and Buhse from Iran. Journal of Essential Oil Bearing Plants, Vol. 7, Issue 2, 120-124.

37. Nafziger Timothy D Jr, Henry Y Fadamiro (2011). Suitability of some farmscaping plants as nectar sources for the parasitoid wasp, Microplitis croceipes (Hymenoptera: Braconidae): Effects on longevity and body nutrients. Biological Control, Vol. 56, Issue 3, 225-229.

38. Nestorović Jasmina, Danijela Mišić, Branislav Šiler, Marina Soković, Jasmina Glamočlija, Ana Ćirić, Vuk Maksimović, Dragoljub Grubišić (2010). Nepetalactone content in shoot cultures of three endemic Nepeta species and the evaluation of their antimicrobial activity. Fitoterapia, Vol. 81, Issue 6, 621-626.

39. Nostro A, MP Germanò, V D’Angelo, A Marino and MA Cannatelli (2000). Extraction methods and bioautography for evaluation of medicinal plant antimicrobial activity. Letters in Applied Microbiology, Vol. 30, Issue 5, 379-384.

40. Nostro Antonia, Maria Angela Cannatelli, Giuseppe Crisafi, Vittorio Alonzo (2001). The effect of Nepeta cataria extract on adherence and enzyme production of Staphylococcus aureus. International Journal of Antimicrobial Agents, Volume 18, Issue 6, 583-585.

41. Nykänen Irma, Yvonne Holm, and Raimo Hiltunen (1989). Composition of the Essential Oil of Agastache foeniculum. Planta medica, Vol. 55, Issue 3, 314-315.

42. Omidbaigi R, F Sefidkon (2003). Essential Oil Composition of Agastache foeniculum cultivated in Iran. Journal of Essential Oil Research, Vol. 15, Issue 1, 52-53.

43. Omidbaigi R, F Sefidkon (2004). Effect of sowing time on the essential oil content and composition of Agastache foeniculum. J. of Essential Oil Bearing Plants, Vol. 7, Issue 2, 190-194

44. Pavela Roman (2005). Insecticidal activity of some essential oils against larvae of Spodoptera littoralis. Fitoterapia, Vol. 76, Issues 7-8, 691-696.
45. Peterson Chris and Joel Coats (2001). Insect repellentspast, present and future. Pesticide Outlook, Vol. 12, Issue 4, 154-158.

46. Peterson CJ, LT Nemetz, LM Jones \& JR Coats (2002). Behavioral activity of catnip (Lamiaceae) essential oil components to the German cockroach (Blattodea: Blattellidae). Journal of Economic Entomology, 95(2), 377-380.

47. Pickett JA, GI Aradottir, GA Birkett, MA Bruce, TJ Chamberlain, K Khan, AOM Charles, ES Lesley and CM Woodcock (2012). Aspects of insect chemical ecology: exploitation of reception and detection as tools for deception of pests and beneficial insects. Physiological Entomology, Vol. 37, Issue 1, 2-9.

48. Polsomboon S, JP Grieco, NL Achee, KR Chauhan, S Tanasinchayakul, J Pothikasikorn \& T Chareonviriyaphap (2008). Behavioral responses of catnip (Nepeta cataria) by two species of mosquitoes, Aedes aegypti and Anopheles harrisoni, in Thailand. Journal of the American Mosquito Control Association, Vol. 24, Issue 4, 513-519.

49. Prescott Thomas AK, Nigel C Veitch, Monique SJ Simmonds (2011). Direct inhibition of calcineurin by caffeoyl phenylethanoid glycosides from Teucrium chamaedrys and Nepeta cataria. Journal of Ethnopharmacology, Volume 137, Issue 3, 1306-1310.

50. Sánchez-Recillas Amanda, Paul Mantecón-Reyes, Patricia Castillo-España, Rafael Villalobos -Molina, Maximiliano Ibarra-Barajas, Samuel Estrada-Soto (2014). Tracheal relaxation of five medicinal plants used in Mexico for the treatment of several diseases. Asian Pacific Journal of Tropical Medicine, Vol. 7, Issue 3, 179-183.

51. Schultz G, E Simbro, J Belden, J Zhu \& J Coats (2004). Catnip, Nepeta cataria (Lamiales: Lamiaceae) - a closer look: seasonal occurrence of nepetalactone isomers and comparative repellency of three terpenoids to insects. Environmental entomology, Vol. 33, Issue 6, 15621569.

52. Senechal NP (1990). Evaluation of native perennial Lamiaceae as sources of nectar for honey bees. Doctoral dissertation, Iowa State University.

53. Shakhnoza S Azimova, Anna I Glushenkova (2012). Lipids, Lipophilic Components and Essential Oils from Plant Sources. Ed. Springer London, ISBN 978-0-85729-322-0, 439.

54. Sherry CJ, PS Hunter (1979). The effect of an ethanol extract of catnip (Nepeta cataria) on the behavior of the young chick. Experientia, Vol. 35, Issue 2, 237-238.

55. Srifi A, B Rahmouni, El H Bouidida, K Alaoui, Y Cherrah (2013). Étude phytochimique et activité antifongique in vitro des huiles essentielles de quatre espèces du genre Nepeta du Maroc. Phytothérapie. Vol. 11, Issue 3, 161-171.

56. Suschke U, F Sporer, J Schneele, HK Geiss \& J Reichling (2007). Antibacterial and cytotoxic activity of Nepeta cataria L., N. cataria var. citriodora (Beck.) Balb. and Melissa officinalis L. essential oils. Natural Product Communications, Vol. 2, Issue 12, 1277-1286. 
57. Tisserand Robert, Rodney Young (2014). 13 - Essential oil profiles. Essential Oil Safety (Second Edition), Churchill Livingstone Elsevier, 187-482.

58. Vogelmann JE (1983). A biosystematic study of Agastache section Agastache (Labiatae) (Doctoral dissertation, Indiana University).

59. Vogelmann JE (1984). Flavonoids of Agastache section Agastache. Biochemical Systematics and Ecology. Vol. 12, Issue 4, 363-366.

60. Vogelmann JE (1985). Crossing relationships among North American and eastern Asian populations of Agastache sect. Agastache (Labiatae). Systematic Botany,Vol. 10, No. 4, 445-452.

61. Wang Mingfu, Ka-Wing Cheng, Qingli Wu and James E. Simon (2007). Quantification of nepetalactones in catnip (Nepeta cataria L.) by HPLC coupled with ultraviolet and mass spectrometric detection. Phytochemical analysis. Vol. 18, Issue 2, 157-160.

62. Widrlechner MP (1992). A field evaluation of native mint family plants as honey bee forage in Iowa. In Proceedings of the Twelfth North American Prairie Conference. University of Northern Iowa, Cedar Falls, 39-42.

63. Wilson LA, NP Senechal, MP Widrlechner (1992). Headspace analysis of the volatile oils of Agastache. Journal of Agricultural and Food Chemistry, Vol. 40, Issue 8, 1362-1366.

64. Woods MW and HG DuBuy (1951). Hereditary and Pathogenic Nature of Mutant Mitochondria in Nepeta. Journal of the national Cancer Institute. 1105-1151.

65. Yashika Bhalla, Vinay Kumar Gupta and Vikas Jaitak (2013). Anticancer activity of essential oils: a review. Journal of the Science of Food and Agriculture. Vol. 93, Issue 15, 3643-3653.
66. Zenasni L, H Bouidida, A Hancali, A Boudhane, H Amzal, A Idrissi, A Aouad, Y Bakri \& A Benjouad (2008). The essentials oils and antimicrobial activity of four Nepeta species from Morocco. Journal of Medicinal Plants Research, 2(5), 111-114.

67. Zhang Hui, Shanshan Lu, Jian Wu, Yi Jiang, Yingmin Lu, Huien Zhao (2014). Effect of substrate depth on 18 nonsucculent herbaceous perennials for extensive green roofs in a region with a dry spring. Ecological Engineering, Vol. 71, 490-500.

68. Zhu J, X Zeng, T Liu, K Qian, Y Han, S Xue, B Tucker, G Schultz, J Coats, W Rowley \& A Zhang (2006). Adult repellency and larvicidal activity of five plant essential oils against mosquitoes. Journal of the American Mosquito Control Association, 22(3), 515-522.

69. Zhu JJ, XP Zeng, D Berkebile, HJ Du, Y Tong and K Qian (2009). Efficacy and safety of catnip (Nepeta cataria) as a novel filth fly repellent. Med and Vet Ent, Vol. 23, Issue 3, 209-216.

70. Zhu JJ, DR Berkebile, CA Dunlap, A Zhang, D Boxler, K Tangtrakulwanich, RW Behle, F Baxendale and G Brewer (2012). Nepetalactones from essential oil of Nepeta cataria represent a stable fly feeding and oviposition repellent. Medical and Veterinary Entomology, Vol. 26, Issue 2, 131-138.

71. Zhu JJ, BJ Wienhold, J Wehrle, D Davis, H Chen, D Taylor, K Friesen and L Zurek (2014). Efficacy and longevity of newly developed catnip oil microcapsules against stable fly oviposition and larval growth. Medical and Veterinary Entomology, Vol. 28, Issue 2, 222-227.

72. Zielińska S and Matkowski A (2014). Phytochemistry and bioactivity of aromatic and medicinal plants from the genus Agastache (Lamiaceae). Phytochem Rev., Vol. 13, 391-416. 